Danukalo M. V., Hancheva O. V., Melnikova O. V., Isachenko M. I. Medullary vasomotor center: a modern view of the structure, function and its role in arterial hypertension pathogenesis. Journal of Education, Health and Sport. 2021;11(08):491-503. eISSN 2391-8306. DOI http://dx.doi.org/10.12775/JEHS.2021.11.08.055

https://apcz.umk.pl/JEHS/article/view/JEHS.2021.11.08.055

https://zenodo.org/record/5567308

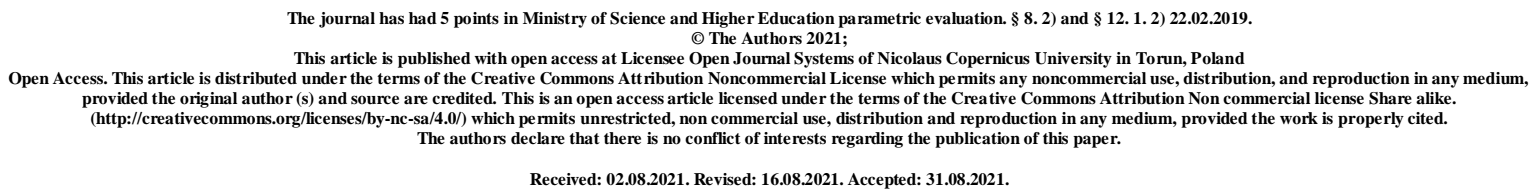

UDC: 616.839.1/.6-06:616.12-008.331.1]-092-07

\title{
MEDULLARY VASOMOTOR CENTER: A MODERN VIEW OF THE STRUCTURE, FUNCTION AND ITS ROLE IN ARTERIAL HYPERTENSION PATHOGENESIS
}

\author{
M. V. Danukalo, O. V. Hancheva, O. V. Melnikova, M. I. Isachenko
}

\section{Zaporizhzhia State Medical University}

Department of Pathological Physiology with the Course of Normal Physiology

Danukalo M. V., MD, PhD, Senior assistant of the Department of Pathological Physiology with the course of normal physiology, Zaporizhzhia State Medical University, Ukraine; ORCID iD: 00000003-3413-945X; Web of Science ResearcherID: AAC-6138-2019

Hancheva O. V., MD, PhD, DSc, Professor, Head of the Department of Pathological Physiology with the course of normal physiology, Zaporizhzhia State Medical University, Ukraine; ORCID iD: 0000-0001-7339-7078; Web of Science ResearcherID: X-9959-2019

Melnikova O. V., MD, PhD, Associate Professor of the Department of Pathophysiology, Zaporizhzhia State Medical University, Ukraine; ORCID: 0000-0002-6807-8440

Isachenko M. I., MD, PhD, Assistant of the Department of Pathological Physiology with the course of normal physiology, Zaporizhzhia State Medical University, Zaporizhzhia, Ukraine; ORCID ID: 0000-0002-3026-1012; Web of Science ResearcherID: Y-1361-2019;

fedotova@zsmu.pp.ua; +380973029038

\section{Abstract}

The medullary centers of blood pressure regulation have been in the field of vision of both physiologists and doctors for a very long period of time. This is mainly due to the abundance of structures and interstructural interactions in the brain stem, involved in maintaining blood pressure. Advances in research technology open new opportunities these days to look at this problem from a different angle. Moreover, research of medullary centers of blood pressure regulation will make it possible to understand better the mechanisms of 
persistent increase in blood pressure, which will create the preconditions for the formation of new pathogenetically substantiated therapeutic approaches in the treatment of such a widespread and dangerous pathology as arterial hypertension. Therefore, the aim of this work was to analyze modern views about the structure and composition of the medullary vasomotor center, its functions and its role in the arterial hypertension development. To achieve this goal, the search by keywords: arterial hypertension, baroreflex, NTS, DMN, RVLM, CVLM, CPA, SHR, LC and analysis of scientific articles from the databases of search engines Google Scholar, Web of Science, Pub Med was done. Conclusions: 1. The analysis of literature sources showed that the concept of "medullar vasomotor center" includes a number of brainstem formations, the most studied of which are the structures of the dorsal complex of the vagus nerve (the nucleus of the solitary tract, the dorsal motor nucleus, area postrema), the rostral and caudal ventrolateral regions of medulla, caudal pressor area, noradrenergic structures of the brainstem, in particular the locus coeruleus, as the biggest of them. 2 . According to literary sources, arterial hypertension is accompanied by the changes in the morphofunctional state of the above-mentioned structures. The most common mechanisms are violation of the neurotransmitter composition within the structure and the neuroinflammatory process.

Key words: brainstem; baroreflex; dorsal vagal complex; caudal ventrolateral medulla; rostral ventrolateral medulla; locus coeruleus; arterial hypertension.

Introduction: Despite the long history of research, neurogenic regulation of blood pressure (BP) to this day remains one of the most controversial issues of modern physiology and pathophysiology. BP in the body is determined by two components: total peripheral vascular resistance and cardiac output [1]. At the same time, the description of specific central structures, which can determine the neurogenic vascular tone and cardiac activity, has been actively pursued to this day since the description of V.F. Ovsyannikov of the fact of pronounced hypotension from transection of the ponto-bulbar region of the brain in experimental animals [2]. Since then, the attention of scientists to the brain stem as the primary center for BP analyzing and its maintaining has only increased. The results of many experiments on the stimulation or destruction of various stem structures have been accumulated in order to clarify their effect on BP. The researches resulted in the allocation of the so-called "medullary vasomotor" center, which included the following structures: components of the dorsal complex $\mathrm{n}$ vagus (nucleus tractus solitarii (NTS), dorsal motor nucleus (DMN), area postrema (AP)), ventromedial and ventrolateral regions of the 
brainstem, a number of nuclei of the stem reticular formations, in particular the reticular gigantocellular nucleus (RGN), as well as the noradrenergic structures of the brainstem (A2, A5, A6 regions). The researchers emphasized that these structures have a complex network of interneuronal connections with the overlying structures of the central nervous system, such as the nuclei of the hypothalamus, structures of the limbic system [3]. The neurons of the bulbar level of the brain stem integrate and interface the function of several systems that maintain the body's homeostasis, including cardiovascular, respiratory, muscular systems. In addition, brainstem coordinates the processes of blood circulation and respiration, their conjunction with heat production, metabolism, and emotional manifestation of the behavioral acts. With the advent of new research methods in modern neurophysiology, scientists can analyze the problem of central BP regulation under a new angle, expanding and deepening knowledge about the mechanisms that underlie it.

Additional relevance to the description of the central mechanisms of BP control is given by the fact that, according to modern concepts, their dysfunction leads to the development of one of the most common disabling diseases - primary arterial hypertension (AH) [4].

Therefore, the aim of this work was to analyze modern views about the structure and composition of the medullary vasomotor center, its functions and its role in the arterial hypertension development.

Matherials and methods: analysis of scientific articles from the databases of search engines Google Scholar, Web of Science, Pub Med search by keywords: arterial hypertension, baroreflex, NTS, DMN, RVLM, CVLM, CPA, SHR, LC.

Structure and function of medullary vasomotor center. Its role in arterial hypertension pathogenesis. Baroreflex control of BP and its alteration in arterial hypertension. Before proceeding to the description of modern concepts of the "medullary vasomotor center" structure and features of the functional state of its components in $\mathrm{AH}$, it is necessary to mention the baroreflex regulation of BP. This mechanism of BP control is activated in response to a wide range of endogenous and exogenous stimuli, which lead to an acute increase or decrease in BP. Subsequent involvement of a number of stem centers of the ANS returns BP to normal values through chrono- and inotropic reactions of the heart and blood vessels [5]. Studies have shown a decrease in baroreflex sensitivity in AH [6]. In addition, dysfunction of the efferent baroreflex arch, caused by either neuronal degeneration (autonomic failure) or ganglionic blockade, causes a marked increase in sensitivity to vasodilators and vasoconstrictor drugs. Now, the studies are underway to determine the 
sensitivity to vasoactive drugs in healthy people and in patients with baroreflex disorders. [7]. To date, the study of baroreflex control of BP is of great practical importance for expanding approaches to the treatment of resistant AH. Thus, two approaches to reduce persistently high BP by stimulating the baroreflex have been detailed and are being actively studied: baroreceptor-activating therapy and endothelial baroreceptor amplification [8].

The role of DVC in BP regulation and morphofunctional changes of its components in AH. Impulses from baroreceptors, are sent to the dorsal vagal complex (DVC) - a complex of interconnected structures of the medulla oblongata that includes the NTS, DMN, and AP. Among them, NTS is the primary afferent link receiving information from the baro- and chemoreceptors of the aortic arch. Later, this nucleus, being a relay link between the sympathetic and parasympathetic divisions of the ANS, activates a number of stem centers depending on the impulses from baroreceptors: with a decrease in their frequency, the structures of the sympathetic link are activated and the tone of the parasympathetic link decreases, with an increase, vice versa. The researchers noted a number of morpho-functional changes in the NTS under AH that relate to impaired neurotransmitter activity $[9,10]$, impaired blood supply [11] and neuroinflammatory processes in the structure [12].

DMN which has close reciprocal links with the NTS is equally important in BP control as the main effector link of the vagus nerve [13].

Several researchers have convincingly shown that lentiviral stimulation of DMN significantly reduces BP [14]. Moreover, the high activity of this structure has a cardioprotective effect, which is especially interesting in the context of the prevention of heart failure after myocardial infarction [15]. At the same time, the presence of such a pathology as $\mathrm{AH}$ alters the functional state of DMN neurons. Thus, it was shown in the experiment that in rats with spontaneous arterial hypertension there is an age-dependent decrease in the number of cardiac preganglionic neurons [16]. Besides several other researchers have established a violation of the expression of adenosine [17], angiotensin type 2 receptors [18], and an imbalance in the expression of nitric oxide synthase isoforms [10].

The third structure of the DVC - area postrema is also important in BP control that is evidenced by the data obtained by Wesley S. Hood et al. Thus, they showed that, in response to isoproterenol-induced hypotension, the expression of c-fos, a well-known marker of functional cell activation, increases in the AP [19]. One of the mechanisms for the realization of the regulatory effect of AP on BP may be a change in the tone of the ANS. Thus, Y. Abukar et al. in their experiments showed that AP destruction decreases the activity of cardiac 
sympathetic neurons [20]. The study of the mechanisms by which AP controls the tone of the ANS is currently an urgent task for many researchers. The influence of gas transmitters $\left(\mathrm{H}_{2} \mathrm{~S}\right)$ [21], cytokines (TNF- $\alpha$, apelin) [22], humoral factors (angiotensin II) [23] on the functional state of the AP structure in arterial hypertension has already been described. On the other hand, the presence of a weak blood-brain barrier in this area creates conditions for modifying the activity of its neurons and exogenous agents. So Marwa E.F Al Mwafy et al showed the effect of excessive consumption of salt, sugar and fat on the histology of AP [24].

\section{The role of RVLM and CVLM in BP regulation and their morphofunctional} changes in AH. Maintaining the constancy of BP is carried out due to the interaction of two opposite mechanisms: pressor and depressor. The pressor system of the vasomotor center includes sympatho-activating neurons, some of which are output reticulospinal neurons, the axons of which form the descending sympatho-activating pathways of the dorsolateral cord of the spinal cord; the depressor system includes structures that carry out constant tonic inhibition of the above mentioned sympatho-activating pathways. These mechanisms are performed by rostral ventrolateral medulla (RVLM) which realizes pressor effect and caudal ventrolateral medulla (CVLM) which, along with RGN, provides depressor effect. Their morphofunctional peculiarities have been described in detail today [25]. RVLM is a region of the brain stem, the neurons of which are projected onto preganglionic sympathetic neurons of the intermediate-lateral group of spinal cord cells, from where excitatory impulses are delivered to the prevertebral and paravertebral sympathetic ganglia and to the adrenal medulla [26]. In addition to RVLM, a number of structures also carry out descending cardiotonic impulses: the rostral ventromedial region, neurons of the sutural nuclei of the caudal part of the brain stem, the A5 group of catecholaminergic neurons in the ventral part of the pons and the paraventricular nucleus of the hypothalamus [27]. In turn, the above-mentioned CVLM carries out constant tonic inhibition of RVLM, thus realizing a depressant effect on cardiovascular innervation [28]. Similar functions, according to a whole series of studies by Aicher, S. A, are also demonstrated by RGN [25]

RVLM is one of the most studied areas of the brainstem in different pathogenetic variants of AH. For example, the state of the RVLM apelinergic system has been described in rats with a primary (SHR) and secondary (L-NAME-induced) AH model [29]. Much attention is paid to the state of the antioxidant system of RVLM neurons. Thus, it was found that low levels of Nrf2 expression (a transcriptional regulator of the antioxidant genes expression) are associated with increased BP and high tone of the sympathetic nervous system in mice [30]. In addition, it has been shown that angiotensin II implements prooxidant activity in astrocytes 
through a decrease in Nrf2 expression in RVLM of rats with hypertension, while the protector protein $\beta$-arrestin 1 , increasing its expression, reduces the intensity of oxidative stress [31, 32]. Moreover, dysfunction of Nrf2 expression in RVLM may be one of the mechanisms of AH development in obesity [33]. INOS plays an important role in the production of reactive oxygen species in RVLM under experimental AH [34]. The interesting fact is shown in the experiment: physical activity can reduce the expression of iNOS in the RVLM, which statistically significantly reduced the SNS activity of experimental animals [35]. Li H.-B et al. studied more broadly the problem of oxidative stress reducing with the help of physical loading and subsequently the decrease of neuroinflammation in RVLM in AH. They showed that physical activity improves neurotransmission, reduces the amount of proinflammatory cytokines, and restores antioxidant activity in RVLM of animals with AH [36]. Most likely, the excess of prooxidants in the RVLM structure in AH is only one of the mechanisms of the increased SNS tone associated with this pathology. For example, Jia-Xiang Wu et al found a relationship between sympathicotonia and dysregulation of the expression of voltagedependent Na channels Nav1.6 in RVLM [37].

On the other hand, the CVLM depressor zone also undergoes morphofunctional changes in AH. Thus, an increase in the amount of nitric oxide in this region of the brainstem was described along with decreased sensitivity of baroreceptors in rats with hypertension [38]. Several researchers have noted a violation of the neurotransmitter composition of CVLM in AH [39].

The role of CPA in BP regulation and its morphofunctional alterations in $\mathrm{AH}$. The caudal pressor area (CPA) is also an important part of the brainstem in the central regulation of BP. The neurons in this area tonically stimulate the activity of RVLM neurons in a predominantly glutamate-dependent way, since this structure was found to contain mRNA, mainly of the vesicular glutamate transporter type 2 (VGlut2) and the isoform of glutamate decarboxylase with a molecular weight of $67 \mathrm{kDa}$ (GAD67) [40]. At present, the possibilities of CPA in BP regulation through connections with the chemoreflex and the commisural part of the NTS are still actively discussed [41]. At the same time, an increased excitability of pressor neurons in the CPA was shown in rats with spontaneous arterial hypertension, which indicates a change in their functional state in comparison with control normotensive animals [42].

The role of $\mathrm{LC}$ in BP regulation and its morphofunctional alterations in $\mathrm{AH}$. The next brainstem structures that maintain BP homeostasis are its noradrenergic nuclei, the largest of which is the locus coeruleus (LC). LC realizes its effect on systemic BP through the 
effect of norepinephrine on $\alpha 1, \alpha 2, \beta$-adrenergic receptors of brain structures; GABA (gamma-aminobutyric acid) has been described as the second most common neurotransmitter in BP [43]. To date, the role of $\mathrm{LC}$ in the regulation of autonomic nervous system activity is well described, that possible mainly due to the presence of interstructural connections of this structure with the hypothalamus and nuclei of the parasympathetic nervous system [44]. Thus, in the paraventricular nucleus of the hypothalamus, $\alpha 1$-adrenergic receptors were found through which an autonomous response to stress is realized, and moreover, inhibitory $\alpha 2$ adrenergic receptors on GABAergic neurons were found in the same nucleus, which have projections onto the already mentioned intermediate-lateral group of spinal cord cells. The latter aspect exactly implements the removal of tonic inhibition of preganglionic fibers of the sympathetic nervous system and provides its additional activation with an increase in the level of NA in the PVN. [43]. In addition to the indicated connections with PVN, interactions of LC with the main efferent links of the parasympathetic nervous system (DMN and nucleus ambiguous) and the key sympathoactivating structure of the brainstem - RVLM are also described [43, 44]. Considering such a diverse influence of LC on BP regulation, it is not surprising that $\mathrm{AH}$ is accompanied by pronounced morpho-functional changes in this nucleus. So, H.R. Olpe et al. showed that the electrical activity of LC neurons decreases in animals with the DOCA-salt model of AH (based on chronic administration of deoxycorticosterone acetate), as well as in rats with spontaneous hypertension [45], M. Koulu M. et al established an increase in the metabolism of catecholamines in spontaneously hypertensive rats [46]. $\mathrm{AH}$ also changes the sensitivity of the $\alpha 2$-adrenergic receptors of LC neurons [47]. The alterations in peptidergic systems may be the next aspect, demonstrating the mechanisms of changes in the functional state of the LC in AH. So, to date, changes in the synthesis of serotonin, galanin, GABA and glutamate, purines, dopamine-beta hydroxylase in this pathology have already been established [48]. In addition to these substances, researchers are showing an active interest in the study of the angiotensinergic and nitricoxidergic systems in LC in AH. Thus, the relationship of the angiotensin system with tyrosine hydroxylase (the key enzyme in the synthesis of HA) LC has been repeatedly demonstrated [49]. Moreover, angiotensin 2 can change the functional state of LC neurons also by inducing a neuroinflammatory process within it with an increase in the content of proinflammatory cytokines (TNF- $\alpha$ and IL-1) and a decrease in the content of anti-inflammatory IL-10 against the background of activation of the transcription factor NFkB. D. Agarwal et al explain these changes by the fact that angiotensin

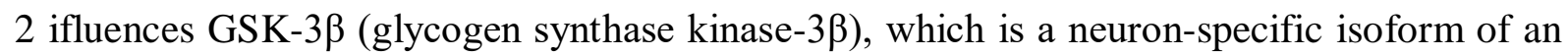
enzyme that induces the formation of pro-inflammatory cytokines NFKB-dependent way [50]. 
As for the nitric oxide system in LC, Sh. Lenner et al demonstrated that NO is an important regulator of tyrosine hydroxylase activity in the experiment by involving NO donors with subsequent measurement of the enzyme activity [51]. Thus, the following can be distinguished among the key mechanisms of the morphofunctional activity changes in LC neurons: neuroinflammatory processes and changes in peptidergic systems in $\mathrm{AH}$.

Prospects for further research and limitations of the review: The problem touched on is too broad for discussion in one article, in the future, it is interesting to dwell in detail on the description and study of the interstructural interactions of stem structures that are involved in BP maintainance, and also to characterize the alterations of these relationships in pathology (AH). In the authors' opinion, special attention should be paid in the future to the description of the etiopathogenetic differences in the morphological and functional features of cardioregulatory stem structures and their interrelationships in $\mathrm{AH}$ of various origins: this will allow us to highlight and focus on the differential approach in the diagnosis and therapy of AH.

Conclusions: 1. The analysis of literary sources showed that the concept of "medullary vasomotor center" includes a number of stem formations, the most studied of which are the following structures: components of the dorsal complex $\mathrm{n}$ vagus (nucleus tractus solitarii, dorsal motor nucleus, area postrema), rostral and caudal ventrolateral regions of the brainstem, caudal pressor area, noradrenergic structures of the brainstem, in particular the locus coeruleus, as the largest of them in area.

2. According to literary sources, arterial hypertension is accompanied by a change in the morphofunctional state of the above-mentioned structures. most often due to violation of the neurotransmitter composition within the structure and the neuroinflammatory process.

\section{REFERENCES:}

1. Campos, R. R., Carillo, B. D. A., Oliveira-Sales, E. B. D., Silva, A. M. D., Silva, N. F. D., Futuro Neto, H. A., \& Bergamaschi, C. T. (2008). Role of the caudal pressor area in the regulation of sympathetic vasomotor tone. Brazilian Journal of Medical and Biological Research, 41(7), 557-562.

2. Cyrlin, V., \& Hrustalev, R. (2001). Rol adrenergicheskikh mekhanizmov mozgovogo stvola i spinnogo mozga $\mathrm{v}$ tsentral`noi regulyatsii krovobrashenia. Vestnik Aritmologii, 22. 
3. Grassi, G., Mark, A., \& Esler, M. (2015). The sympathetic nervous system alterations in human hypertension. Circulation research, 116(6), 976-990. DOI: 10.1161/CIRCRESAHA.116.303604

4. Bakris, G., Ali, W., \& Parati, G. (2019). ACC/AHA versus ESC/ESH on hypertension guidelines: JACC guideline comparison. Journal of the American College of Cardiology, 73(23), 3018-3026.

5. Zhilyaiev, S., Platonova, T., Alekseeva, O., Nikitina, E., \& Demchenko, I. (2019). Adaptivnie mekchanizmi baroreflectornoi regulyatsii serdechno-sosudistoi sistemy pri ekstremal`noi giperoksii. Zurnal Evolutsionnoi Biokhimii I Fiziologii, 55(5), 316-323.

6. Man, T., Tegegne, B. S., van Roon, A. M., Rosmalen, J. G., Nolte, I. M., Snieder, H., \& Riese, H. (2021). Spontaneous baroreflex sensitivity and its association with age, sex, obesity indices and hypertension: a population study. American journal of hypertension.

7. Grilletti, J. V. F., Scapini, K. B., Bernardes, N., Spadari, J., Bigongiari, A., Mazuchi, F. D. A., ... \& De Angelis, K. (2018). Impaired baroreflex sensitivity and increased systolic blood pressure variability in chronic post-ischemic stroke. Clinics, 73.

8. Koziolek, M., Beige, J., Wallbach, M., Zenker, D., Henning, G., Halbach, M., ... \& Reuter, H. (2017). Baroreceptor activation therapy for therapy-resistant hypertension: indications and patient selection: recommendations of the BAT consensus group 2017. Der Internist, 58(10), 1114-1123.

9. Sved, A. F., Imaizumi, T. S. U. T. O. M. I., Talman, W. T., \& Reis, D. J. (1985). Vasopressin contributes to hypertension caused by nucleus tractus solitarius lesions. Hypertension, 7(2), 262-267. 10.1161/01.HYP.7.2.262.

10. Danukalo, M. V., \& Hancheva, O. V. (2020). Isoform profile of NOS enzyme in structure of rats' solitary-vagal complex in arterial hypertension of various origin. DOI: 10.14739/2409-2932.2020.1.198141

11. Hosford, P. S., Millar, J., Ramage, A. G., \& Marina, N. (2017). Abnormal oxygen homeostasis in the nucleus tractus solitarii of the spontaneously hypertensive rat. Experimental physiology, 102(4), 389-396. DOI: 10.1113/EP086023

12. Foulquier, S. (2020). Brain perivascular macrophages: connecting inflammation to autonomic activity in hypertension. Hypertension Research, 43(2), 148-150. DOI: $10.1038 / \mathrm{s} 41440-019-0359-7$

13. Nucleus of the solitary tract catecholaminergic neurons modulate the cardiovascular response to psychological stress in rats / D. L. Daubert, M McCowan, B Erdos 
et al. The Journal of physiology. 2012. Vol. 590. № 19. P. 4881-4895. DOI: 10.1113/jphysiol.2012.232314

14. Van Kleef, M. E., Visseren, F. L., Vernooij, J. W., Nathoe, H. M., Cramer, M. J. M., Bemelmans, R. H., ... \& SMART-Study Group. (2018). Four ECG left ventricular hypertrophy criteria and the risk of cardiovascular events and mortality in patients with vascular disease. Journal of hypertension, 36(9), 1865-1873. DOI: 10.1097/HJH.0000000000001871

15. Gorky, J., Vadigepalli, R., \& Schwaber, J. (2018). Transcriptional Profiling of Laser Captured Neurons in the Dorsal Motor Nucleus of the vagus in Response to Ischemic Heart Failure. The FASEB Journal, 32, 580-11.

16. Corbett, E. K., Mary, D. A., McWilliam, P. N., \& Batten, T. F. (2007). Agerelated loss of cardiac vagal preganglionic neurones in spontaneously hypertensive rats. Experimental physiology, 92(6), 1005-1013. DOI: 10.1113/expphysiol.2007.038216

17. Krstew, E., Jarrott, B., \& Lawrence, A. J. (1998). Autoradiographic visualisation of axonal transport of adenosine A1 receptors along the rat vagus nerve and characterisation of adenosine A1 receptor binding in the dorsal vagal complex of hypertensive and normotensive rats. Brain research, 802(1-2), 61-68. DOI: 10.1016/S0006-8993(98)005678

18. Ruchaya, P. J., Speretta, G. F., Blanch, G. T., Li, H., Sumners, C., Menani, J. V., ... \& Colombari, D. S. (2016). Overexpression of AT2R in the solitary-vagal complex improves baroreflex in the spontaneously hypertensive rat. Neuropeptides, 60, 29-36. DOI: 10.1016/j.npep.2016.06.006

19. Hood, W. S., Thunhorst, R. L., \& Curtis, K. (2020, September). Neuronal activation in nucleus tractus solitarius and area postrema of young and aged female rats induced by hypotension. In Oklahoma State University Center for Health Sciences Research Day 2020.

20. Abukar, Y., Ramchandra, R., Hood, S. G., McKinley, M. J., Booth, L. C., Yao, S. T., \& May, C. N. (2018). Increased cardiac sympathetic nerve activity in ovine heart failure is reduced by lesion of the area postrema, but not lamina terminalis. Basic research in cardiology, 113(5), 1-11.

21. Smith, P. M., Wang, S. J., \& Ferguson, A. V. (2017). Hydrogen Sulfide Decreases Blood Pressure by Influencing the Excitability of Area Postrema Neurons. The FASEB Journal, 31, 1012-9. 
22. Korim, W. S., Elsaafien, K., Basser, J. R., Setiadi, A., May, C. N., \& Yao, S. T. (2019). In renovascular hypertension, TNF- $\alpha$ type- 1 receptors in the area postrema mediate increases in cardiac and renal sympathetic nerve activity and blood pressure. Cardiovascular research, 115(6), 1092-1101.

23. Fink, G. D., Bruner, C. A., \& Mangiapane, M. L. (1987). Area postrema is critical for angiotensin-induced hypertension in rats. Hypertension, 9(4), 355-361.

24. Al Mwafy, M. E., El-Sawaf, M. E. S., Salem, M. F., \& Naguib, Y. M. (2020). Effect of different diets on left ventricle and area postrema in adult male albino rats predisposed to prolonged intake of high salt. Tanta Medical Journal, 48(1), 28.

25. Aicher, S. A. (2003). The gigantocellular depressor area revisited. Cellular and molecular neurobiology, 23(4), 479-490.

26. Barman, S. M., \& Gebber, G. L. (1985). Axonal projection patterns of ventrolateral medullospinal sympathoexcitatory neurons. Journal of Neurophysiology, 53(6), $1551-1566$.

27. Yang, Z., \& Coote, J. H. (1998). Influence of the hypothalamic paraventricular nucleus on cardiovascular neurones in the rostral ventrolateral medulla of the rat. The Journal of Physiology, 513(2), 521-530.

28. Ghali, M. G. Z. (2017). The brainstem network controlling blood pressure: an important role for pressor sites in the caudal medulla and cervical spinal cord. Journal of hypertension, 35(10), 1938-1947.

29. Griffiths, P. R., Lolait, S. J., Pearce, L. E., McBryde, F. D., Paton, J. F., \& O'Carroll, A. M. (2018). Blockade of rostral ventrolateral medulla apelin receptors does not attenuate arterial pressure in SHR and L-NAME-induced hypertensive rats. Frontiers in physiology, 9, 1488.

30. Gao, L., Zimmerman, M. C., Biswal, S., \& Zucker, I. H. (2017). Selective Nrf2 gene deletion in the rostral ventrolateral medulla evokes hypertension and sympathoexcitation in mice. Hypertension, 69(6), 1198-1206.

31. Mowry, F. E., Peaden, S. C., \& Biancardi, V. C. (2020). Cell-Type Specific Angiotensin II-Driven Nrf2 Impairment within Central Cardioregulatory Nuclei of Spontaneously Hypertensive Rats. The FASEB Journal, 34(S1), 1-1.

32. Tan, X., Jiao, P. L., Sun, J. C., Wang, W., Ye, P., Wang, Y. K., ... \& Wang, W. Z. (2021). $\beta$-arrestin1 reduces oxidative stress via Nrf2 activation in the rostral ventrolateral medulla in hypertension. Frontiers in neuroscience, 15, 317. 
33. Balasubramanian, P., Asirvatham-Jeyaraj, N., Monteiro, R., Sivasubramanian, M. K., Hall, D., \& Subramanian, M. (2020). Obesity-induced sympathoexcitation is associated with Nrf2 dysfunction in the rostral ventrolateral medulla. American Journal of Physiology-Regulatory, Integrative and Comparative Physiology, 318(2), R435-R444.

34. Chan, J. Y., \& Chan, S. H. (2019). Differential impacts of brain stem oxidative stress and nitrosative stress on sympathetic vasomotor tone. Pharmacology \& therapeutics, 201, 120-136.

35. de Ataides Raquel, H., Guazelli, C. F. S., Verri Jr, W. A., Michelini, L. C., \& Martins-Pinge, M. C. (2021). Swimming training reduces iNOS expression, augments the antioxidant defense and reduces sympathetic responsiveness in the rostral ventrolateral medulla of normotensive male rats. Brain Research Bulletin, 170, 225-233.

36. Li, H. B., Huo, C. J., Su, Q., Li, X., Bai, J., Zhu, G. Q., \& Kang, Y. M. (2018). Exercise training attenuates proinflammatory cytokines, oxidative stress and modulates neurotransmitters in the rostral ventrolateral medulla of salt-induced hypertensive rats. Cellular Physiology and Biochemistry, 48(3), 1369-1381.

37. Wu, J. X., Tong, L., Hu, L., Xia, C. M., Li, M., Chen, Q. H., ... \& Du, D. S. (2018). Upregulation of Nav1. 6 expression in the rostral ventrolateral medulla of stressinduced hypertensive rats. Hypertension Research, 41(12), 1013-1022.

38. de Castro, U. G. M., de Sousa, G. G., do Pilar Machado, R., Isoldi, M. C., Silva, M. E., Nadu, A. P., ... \& Alzamora, A. C. (2012). Nitric oxide at the CVLM is involved in the attenuation of the reflex bradycardia in renovascular hypertensive rats. Nitric Oxide, 26(2), 118-125.

39. Muratani, H. I. R. O. M. I., Ferrario, C. M., \& Averill, D. B. (1993). Ventrolateral medulla in spontaneously hypertensive rats: role of angiotensin II. American Journal of Physiology-Regulatory, Integrative and Comparative Physiology, 264(2), R388R395.

40. Takakura, A. C., Moreira, T. S., Menani, J. V., Campos, R. R., \& Colombari, E. (2007). Commissural nucleus of the solitary tract is important for cardiovascular responses to caudal pressor area activation. Brain research, 1161, 32-37.

41. Yajima, Y., Ito, S., Komatsu, K., Tsukamoto, K., Matsumoto, K., \& Hirayama, A. (2008). Enhanced response from the caudal pressor area in spontaneously hypertensive rats. Brain research, 1227, 89-95. 
42. Samuels, E. R., \& Szabadi, E. (2008). Functional neuroanatomy of the noradrenergic locus coeruleus: its roles in the regulation of arousal and autonomic function part I: principles of functional organisation. Current neuropharmacology, 6(3), 235-253.

43. Kostijuk, P. (1983). Chastnaya fiziologija nervnoi sistemi (p. 733p.). Leningrad: Nauka.

44. Grindstaff, R. J., Grindstaff, R. R., Sullivan, M. J., \& Cunningham, J. T. (2000). Role of the locus ceruleus in baroreceptor regulation of supraoptic vasopressin neurons in the rat. American Journal of Physiology-Regulatory, Integrative and Comparative Physiology, 279(1), R306-R319.

45. Olpe, H. R., Berecek, K., Jones, R. S. G., Steinmann, M. W., Sonnenburg, C., \& Hofbauer, K. G. (1985). Reduced activity of locus coeruleus neurons in hypertensive rats. Neuroscience letters, 61(1-2), 25-29. DOI: 10.1016/0304-3940(85)90395-7

46. Koulu, M., Saavedra, J. M., Niwa, M., \& Linnoila, M. (1986). Increased catecholamine metabolism in the locus coeruleus of young spontaneously hypertensive rats. Brain research, 369(1-2), 361-364.

47. Kunkler, P. E., Wang, G. M., \& Hwang, B. H. (1994). Galanin-containing neurons in the solitary nucleus and locus coeruleus of spontaneously hypertensive rats are associated with genetic hypertension. Brain research, 651(1-2), 349-352. DOI: 10.1016/00068993(94)90718-8.

48. Kaehler, S. T., Singewald, N., \& Philippu, A. (1999). Release of serotonin in the locus coeruleus of normotensive and spontaneously hypertensive rats (SHR). NaunynSchmiedeberg's archives of pharmacology, 359(6), 460-465.

49. Ogier, M., Bricca, G., Bader, M., \& Bezin, L. (2016). Locus coeruleus dysfunction in transgenic rats with low brain angiotensinogen. CNS neuroscience \& therapeutics, 22(3), 230-237.

50. Agarwal, D., Dange, R. B., Raizada, M. K., \& Francis, J. (2013). Angiotensin II causes imbalance between pro-and anti-inflammatory cytokines by modulating GSK-3 $\beta$ in neuronal culture. British journal of pharmacology, 169(4), 860-874. DOI: 10.1111/bph.12177

51. Lerner, S., Anderzhanova, E., Verbitsky, S., Eilam, R., Kuperman, Y., Tsoory, M., ... \& Erez, A. (2019). ASL metabolically regulates tyrosine hydroxylase in the nucleus locus coeruleus. Cell reports, 29(8), 2144-2153. DOI: 10.1016/j.celrep.2019.10.043 